06

\title{
Рентгеноструктурное исследование аморфно-кристаллического фазового перехода в $\mathrm{Ni}$
}

\author{
() Д.Ю. Ковалев, И.И. Чуев \\ Институт структурной макрокинетики и проблем материаловедения им. А.Г. Мержанова РАН, \\ 142432 Черноголовка, Россия \\ e-mail: kovalev@ism.ac.ru
}

Поступило в Редакцию 31 января 2020 г.

В окончательной редакции 24 апреля 2020 г.

Принято к публикации 24 апреля 2020 г.

Методом высокотемпературной рентгенографии получены систематические данные о аморфно-кристаллическом переходе в $\mathrm{Ni}$. Установлено, что аморфная структура наноразмерных частиц $\mathrm{Ni}$ стабильна до температуры $200^{\circ} \mathrm{C}$. В температурном интервале $300-600^{\circ} \mathrm{C}$ происходит образование нанокристаллов $\mathrm{Ni}$, размер областей когерентного рассеяния которых составляет $5-15 \mathrm{~nm}$ в зависимости от температуры изотермического отжига. Выполнена оценка величины энергии активации роста нанокристаллов, составившая $67.3 \mathrm{~kJ} / \mathrm{mol}$. Установлена зависимость параметра элементарной ячейки нанокристаллического Ni от размера ОКР. С увеличением ОКР у нанокристаллических частиц Ni наблюдается рост метрики ячейки.

Ключевые слова: аморфный $\mathrm{Ni}$, кристаллизация, области когерентного рассеяния, температурная рентгенография.

DOI: $10.21883 / J T F .2020 .10 .49805 .37-20$

\section{Введение}

Аморфные металлы и сплавы являются твердыми телами, в которых отсутствует дальний порядок атомной структуры [1-4]. Аморфные металлические материалы обладают уникальными магнитными [5-8] и механическими [9-12] свойствами, которые сложно получить в кристаллических соединениях. Эти материалы могут применяться в устройствах для хранения данных [13], перспективны в качестве материалов для медицинских имплантатов [14-17] и катализаторов [18-23]. Использование аморфных порошков металлов в качестве реагентов может значительно увеличить скорость реакции твердофазных реакций, например, в интерметаллидных системах. Методы получения аморфных металлических сплавов разнообразны и включают спиннингование [24], ионное облучение [25,26], механическое сплавление [27,28]. Среди химических методов получения аморфных металлических наночастиц $\mathrm{Fe}, \mathrm{Ni}, \mathrm{Ag}$ следует отметить ультразвуковую обработку карбонильных или нитратных растворов металлов в инертной среде [29-31] и восстановление солей металлов борогидридами [32].

Аморфные металлы и сплавы термодинамически нестабильны и могут переходить в кристаллическое состояние при нагреве и механической деформации [33-37]. Кристаллизация аморфных металлов и сплавов представляет интерес для различных применений [34]. Стабильность аморфных металлических материалов при повышенных температурах определяет их функциональные свойства. Настоящая работа посвящена исследованию аморфно-кристаллического перехода в $\mathrm{Ni}$, который используется в качестве основы для катализаторов химических реакций в процессах гидрокрекинга [38].
Стабильность Ni-катализаторов является важным вопросом также в процессах получения водорода из этанола [39-41]. Известно, что на каталитические свойства аморфных Ni-B- сплавов существенное влияние оказывает температура отжига $[42,43]$. Целью настоящей работы является исследование эволюции структуры аморфного порошка Ni при нагреве, определение температурно-временных условий его стабильности и кинетики перехода в нанокристаллическое состояние.

\section{1. Материалы и методика эксперимента}

В качестве исходного материала в экспериментах использовался порошок аморфного никеля, полученный методом жидкофазного химического восстановления нитрата никеля $\mathrm{Ni}\left(\mathrm{NO}_{3}\right)_{2} \cdot 6 \mathrm{H}_{2} \mathrm{O}$ борогидридом натрия $\mathrm{NaBH}_{4}$. Удельная поверхность порошка составляла $200 \mathrm{~g} / \mathrm{m}^{2}$. Морфологию порошка аморфного никеля исследовали методом растровой электронной микроскопии (РЭМ) на автоэмиссионном сканирующем электронном микроскопе сверхвысокого разрешения Zeiss Ultra Plus на базе Ultra 55 (Carl Zeiss AG, Германия).

Температурные исследования аморфно-кристаллического перехода в Ni проводили „in situ“ в высокотемпературной вакуумной камере НТК2000 „Anton Paar“ (Anton Paar $\mathrm{GmbH}$, Австрия) на рентгеновском дифрактометpe ARLX'TRA (Thermo Fisher Scientific, Швейцария) в интервале температур 200-800 ${ }^{\circ}$. Для регистрации дифрактограмм использовалось $\mathrm{Cu} K_{\alpha}$-излучение. Время изотермической выдержки при каждой температуре составляло $5 \mathrm{~h}$. Слой порошка $\mathrm{Ni}$ толщиной около $100 \mu \mathrm{m}$ 
наносили на поверхность вольфрамовой пластины-нагревателя. Далее проводили вакуумирование камеры до давления $2 \cdot 10^{-3} \mathrm{~Pa}$. Отжиг осуществляли в диапазоне температур $200-800^{\circ} \mathrm{C}$ с шагом $100^{\circ} \mathrm{C}$. Регистрацию дифрактограмм проводили в режиме пошагового сканирования в интервале углов $2 \theta=39^{\circ}-56^{\circ}$, шагом съемки $0.02^{\circ}$ и временем набора $2 \mathrm{~s}$ в точке, без вращения образца. Выбор узкого углового интервала регистрации был обусловлен тем, что интенсивности линий $\mathrm{Ni}$ c большими индексами Миллера $h k l$ (220, 311, 222 и т.д.) существенно ниже по сравнению с линиями 111 и 200. На дифрактограммах нанокристаллического $\mathrm{Ni}$ линии на дальних углах размыты, и их интенсивность находится на уровне фона. Скорость нагрева до температуры изотермической выдержки составляла $300^{\circ} \mathrm{C} / \mathrm{min}$. Режим нагрева задавали контроллером Eurotherm 2604 (Eurotherm Ltd, Англия), датчиком которого служила термопара BP5 $\backslash 20$, приваренная к нижней поверхности вольфрамового нагревателя. При максимальной температуре $800^{\circ} \mathrm{C}$ остаточное давление в камере составляло $5 \cdot 10^{-3} \mathrm{~Pa}$. Условия регистрации дифрактограмм были идентичны для всех образцов. Профильный анализ рентгенограмм, снятых после изотермической выдержки при температурах $400-800^{\circ} \mathrm{C}$ в течение $5 \mathrm{~h}$, проводили методом Ритвельда в программном пакете FULLPROF [44].

В качестве исходной модели для уточнения использовались структурные данные $\mathrm{Ni}$ [45], приведенные в Crystallography Open Database (COD ID 9008476) [46]. Аппроксимация профиля пиков проводилась функцией Thompson-Cox-Hastings pseudo-Voigt [47]. Расчет размера областей когерентного рассеяния (ОКР) и величин микронапряжения $(\varepsilon, \%)$ проводился на основании анализа интегральной ширины пиков по процедуре, встроенной в комплекс программ FULLPROF.

Уточнялись профильные параметры рефлексов, фон, параметры элементарной ячейки и изотропные тепловые параметры. Взвешенный $\left(R_{w p}\right)$ фактор расхождения с учетом фона для всех образцов находился в интервале: $R_{w p}=9.6-27 \%$. При финальном уточнении структурных параметров ориентировались на минимальные значения Брэгговских $\left(R_{\mathrm{B}}\right)$ факторов расхождения $R_{\mathrm{B}}=0.4-3 \%$. Высокая степень аморфности фазы $\mathrm{Ni}$ приводит к заметному ухудшению качества дифрактограмм. Это отражается в росте величины фактора расходимости $R_{\exp }$ при переходе от образцов с высокой температурой отжига $\left(800^{\circ} \mathrm{C}, R_{\exp }=6 \%\right)$ к более аморфным образцам с менышей температурой отжига $\left(400^{\circ} \mathrm{C}\right.$, $R_{\exp }=27 \%$ ). Инструментальный фактор учитывали по уширению линий $\mathrm{Ni}$, полученному в результате отжига при $800^{\circ} \mathrm{C}$.

\section{2. Результаты и их обсуждение}

По данным рентгенофазового анализа исходный порошок $\mathrm{Ni}$ при нормальных условиях является аморфным (рис. 1,a). Частицы преимущественно имеют сфе- рическую форму с диаметром 15-150 nm (рис. $1, b)$. На рис. 2 представлены дифракционные картины при нагреве исследуемого порошка Ni. Последовательность рентгенограмм отображена в виде двухмерного поля в координатах угол-время, а интенсивность линии соответствует цветовой гамме поля. Первая и последняя дифрактограммы каждого поля соответствуют съемке при $25^{\circ} \mathrm{C}$ исходного и конечного порошка. В области $2 \theta=40.2^{\circ}$ наблюдается линия материала нагревателя $W$ с индексами Миллера 110. Анализ дифракционной картины при нагреве аморфного порошка $\mathrm{Ni}$ показывает, что при температуре ниже $200^{\circ} \mathrm{C}$ материал сохраняет аморфную структуру. Кристаллизация начинается при температуре $300^{\circ} \mathrm{C}$. На температурных дифрактограммах, полученных при нагреве образцов выше $300^{\circ} \mathrm{C}$, появляются размытые линии 111 и $200 \mathrm{Ni}$. С увеличением времени и температуры отжига интенсивность линий возрастает, а их полуширина уменьшается. Дифрактограммы порошка после изотермической выдержки при $300-600^{\circ} \mathrm{C}$ показывают, что $\mathrm{Ni}$ находится в нанокристаллическом состоянии (рис. 3).

На основе полнопрофильного ритвельдовского анализа температурных дифрактограмм получены данные о кинетике изменения размеров ОКР, которая характеризует переход $\mathrm{Ni}$ из аморфного в нанокристаллическое состояние (рис. 4). Дифрактограммы, полученные при температуре менее $300^{\circ} \mathrm{C}$, не обрабатывались из-за высокой степени аморфности образца. Последние точки на рис. 4 в температурных сериях, соответствующие времени $\sim 300 \mathrm{~min}$, получены для образцов, охлажденных после отжига до комнатной температуры.

При оценке размеров ОКР $\mathrm{Ni}$ при изотермической выдержке на основе анализа интегральной ширины пика мы столкнулись с заметным статистическим разбросом значений ОКР. Относительная статистическая погрешность изменяется от $50 \%$ при $400^{\circ} \mathrm{C}$ до $18 \%$ при $800^{\circ} \mathrm{C}$. При температурах отжига 400 и $500^{\circ} \mathrm{C}$ основной вклад в дисперсию вносит несовершенство образцов, связанное с их аморфностью - низкие интенсивности и широкие профили пиков при большом значении фона. При температурах более $600^{\circ} \mathrm{C}$ отклонения в результатах связаны с чувствительностью метода измерения интегральной ширины пика к самой процедуре уточнения по методу Ритвельда. Поскольку анализировался угловой интервал только с двумя дифракционными линиями 111 и $200 \mathrm{Ni}$, сокращение экспериментального массива данных привело к высокой степени корреляции между уточняемыми параметрами профиля. Сильное влияние корреляций не позволяет обсуждать абсолютные значения величин ОКР, поэтому в настоящей работе делается акцент на изучении тенденций в изменении этих величин. Для того чтобы сгладить влияние пиковых отклонений в расчетах, внутри каждой температурной серии нагрева данные обрабатывались медианным фильтром с окном, равным 3.

Анализ графиков (рис. 4) показывает, что при $T=400-600^{\circ} \mathrm{C}$ не наблюдается изменение размера 

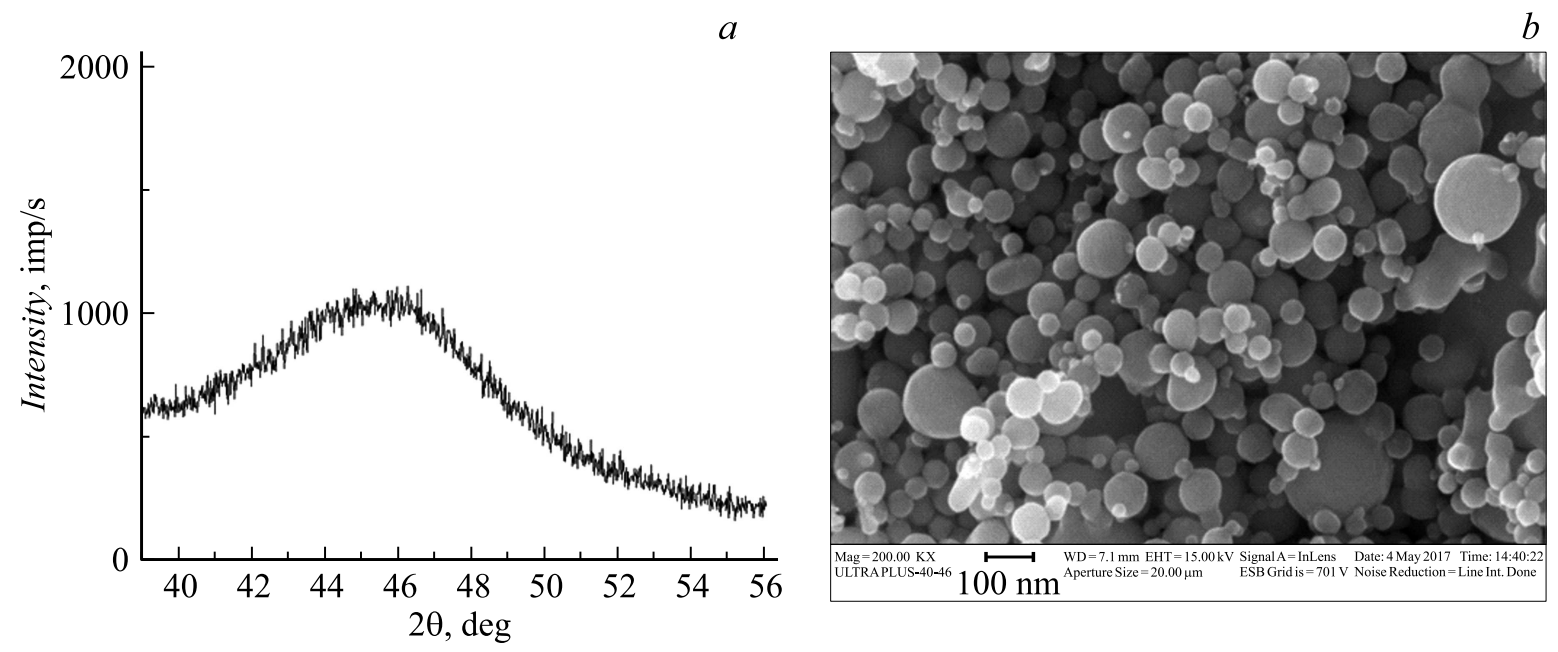

Рис. 1. Дифрактограмма (a) и РЭМ (b) аморфного порошка $\mathrm{Ni}$ при $25^{\circ} \mathrm{C}$.
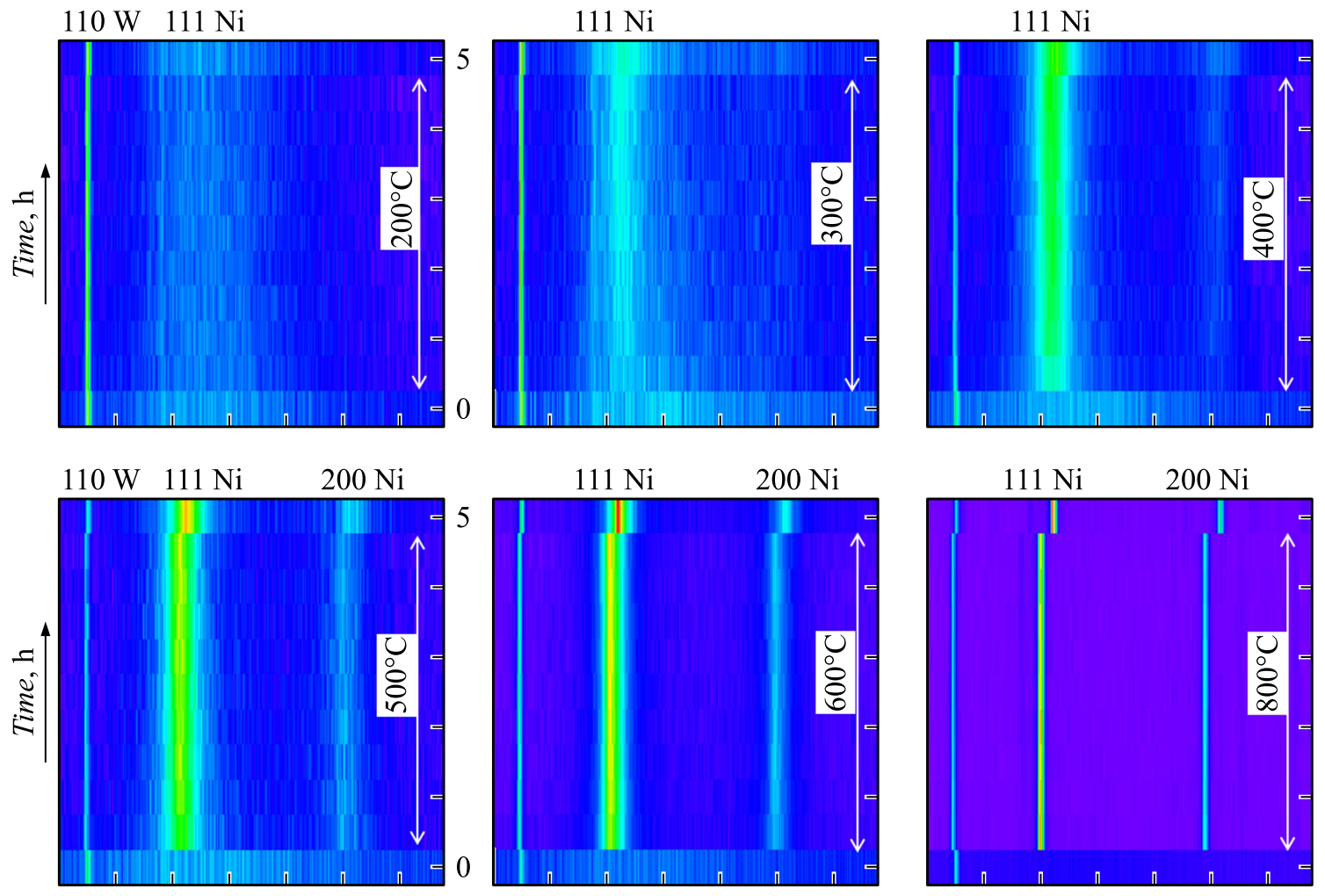

39

$56 \quad 39$

$2 \theta, \operatorname{deg}$

$2 \theta, \operatorname{deg}$

$56 \quad 39$

Рис. 2. $2 D$ визуализация дифракционной картины при нагреве аморфного $\mathrm{Ni}$.
ОКР от времени отжига. Нанокристаллы Ni формируются в течение $30 \mathrm{~min}$ отжига. Размер ОКР находится интервале от 5(3) до $15(5) \mathrm{nm}$. При $T=700^{\circ} \mathrm{C}$ кинетика меняется: наблюдается монотонный рост ОКР от $30(9)$ до $70(9) \mathrm{nm}$. При достижении $800^{\circ} \mathrm{C}$ размер ОКР в первые $30 \mathrm{~min}$ принимает значение 90(7) nm и мало меняется в течение времени. После охлаждения образцов, отожженных при $T=700$ и $800^{\circ} \mathrm{C}$, полуширина дифракционных линий $\mathrm{Ni}$ сопоставима с по- лушириной линий эталонного микрокристаллического $\mathrm{LaB}_{6}$. Поскольку верхняя граница определения размера кристаллита связана с инструментальным разрешением дифрактометра, для качественной оценки результатов значения размеров ОКР для 700 и $800^{\circ} \mathrm{C}$ были приняты равными $300 \mathrm{~nm}$.

Таким образом, при температурах до $600^{\circ} \mathrm{C}$ происходит медленное увеличение размера ОКР до $15 \mathrm{~nm}$, а при дальнейшем повышении температуры происходит скачок 

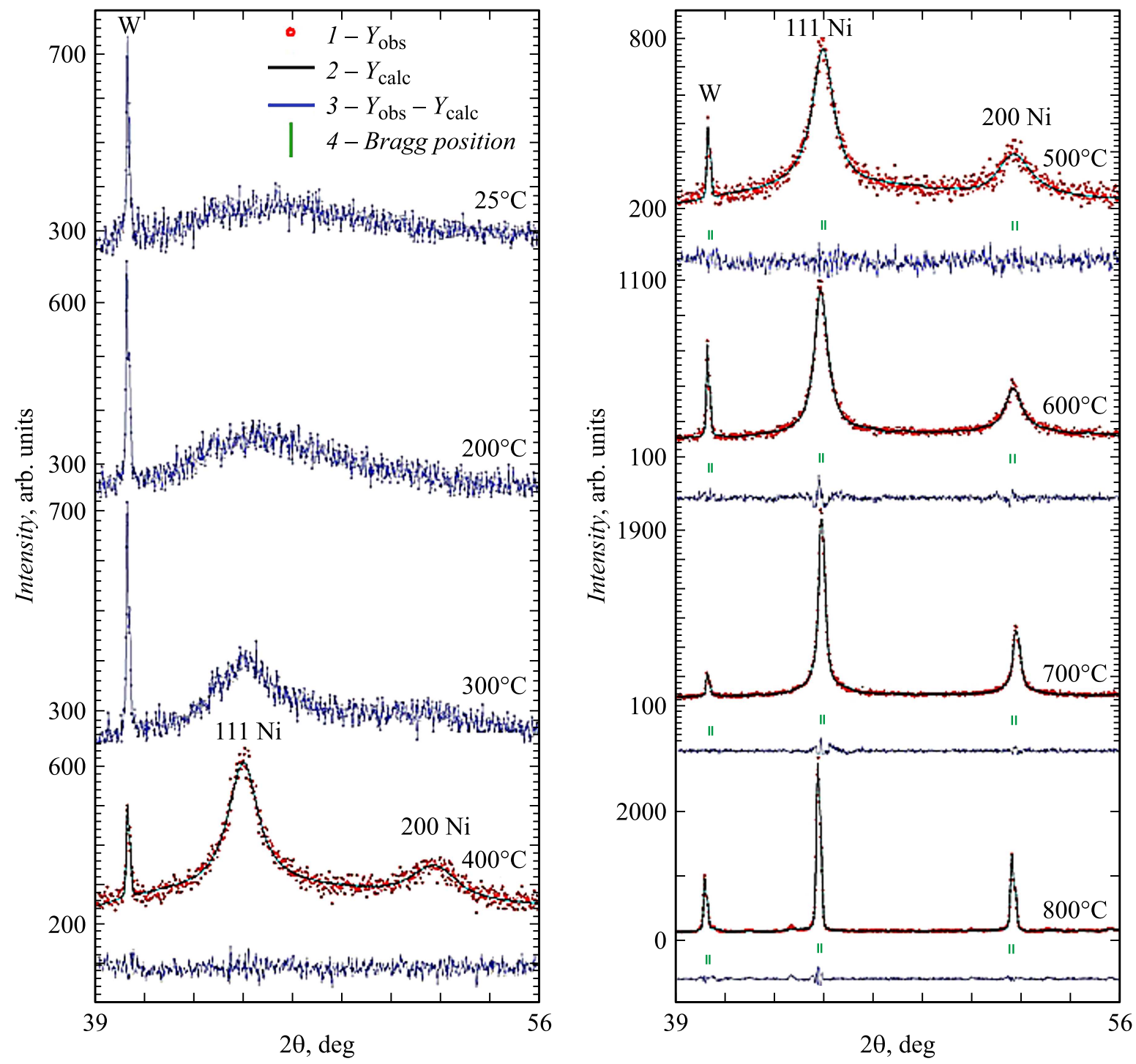

Рис. 3. Экспериментальные $\left(200-800^{\circ} \mathrm{C}\right)$, расчетные и разностные $\left(400-800^{\circ} \mathrm{C}\right)$ дифрактограммы порошка Ni после изотермической выдержки при температурах $200-800^{\circ} \mathrm{C}$ в течение $5 \mathrm{~h}$.

размера ОКР до $70-90 \mathrm{~nm}$. Вероятно, это связано с влиянием дисперсности аморфной матрицы на кинетику роста кристаллов. Морфология аморфного порошка $\mathrm{Ni}$ свидетельствует о том, что размер частиц $\mathrm{Ni}$ находится в интервале от 15 до $150 \mathrm{~nm}$ (рис. $1, b$ ). Тогда размер ОКР $(15 \mathrm{~nm})$ при $600^{\circ} \mathrm{C}$ становится сравнимым с минимальным размером частиц. Дальнейший рост ОКР при повышении температуры отжига до $700-800^{\circ} \mathrm{C}$ связан с коалесценцией частиц, что приводит к замедлению кинетики роста кристаллитов.

На рис. 5 приведены температурные зависимости рассчитанных величин микронапряжений $(\varepsilon, \%)$ и размеров ОКР $(L, \mathrm{~nm})$, усредненных внутри каждой серии изотермической выдержи. Из графика видно, что величина микронапряжений $(\varepsilon)$ линейно и монотонно уменьшается с ростом температуры, в то время как величина размера ОКР $(L)$ показывает экспоненциаль- ный рост при температурах больше $600^{\circ} \mathrm{C}$. Аналогичный характер зависимости был получен при исследовании процесса кристаллизации железа [48], при этом благодаря механическому измельчению порошка величины $\varepsilon(0.19-0.74 \%)$ [48] заметно превышают $\varepsilon$, полученные в нашем исследовании $\left(3 \cdot 10^{-4}-4 \cdot 10^{-2} \%\right)$ для образцов, синтезированных методом жидкофазного химического восстановления. Поскольку на графиках зависимости $\varepsilon(T)$ в отличие от $L(T)$, не наблюдается никаких качественных изменений, которые бы характеризовали фазовый переход из аморфного в кристаллическое состояние, мы предположили, что изменения $\varepsilon$ нечувствительны к процессу роста кристаллов, поэтому в настоящей работе мы анализируем только изменения $L$ от температуры. Анализ этих изменений (размер ОКР от температуры отжига) был проведен в предположении аррениусовской зависимости, т.е. рост нанокристаллов 


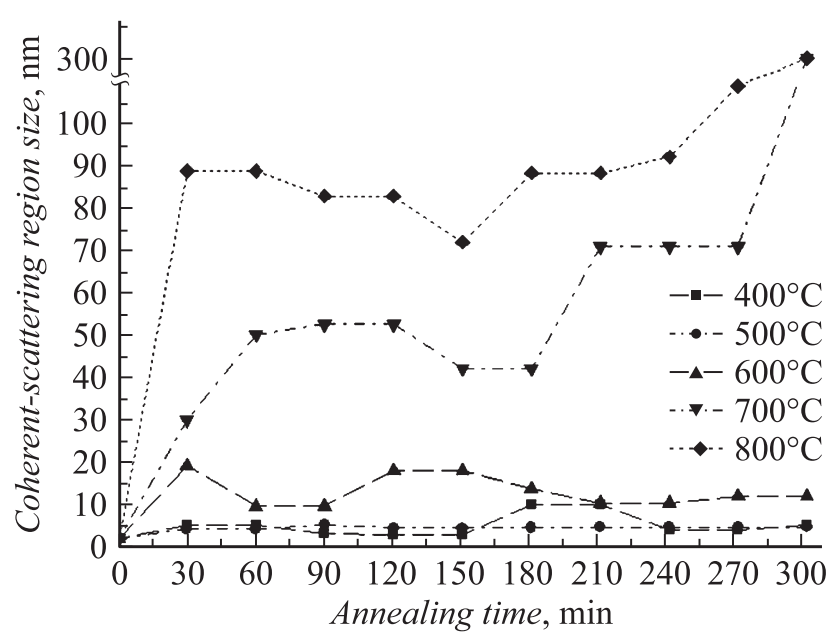

Рис. 4. Кинетика изменения размера ОКР Ni при изотермических отжигах $400-800^{\circ} \mathrm{C}$.

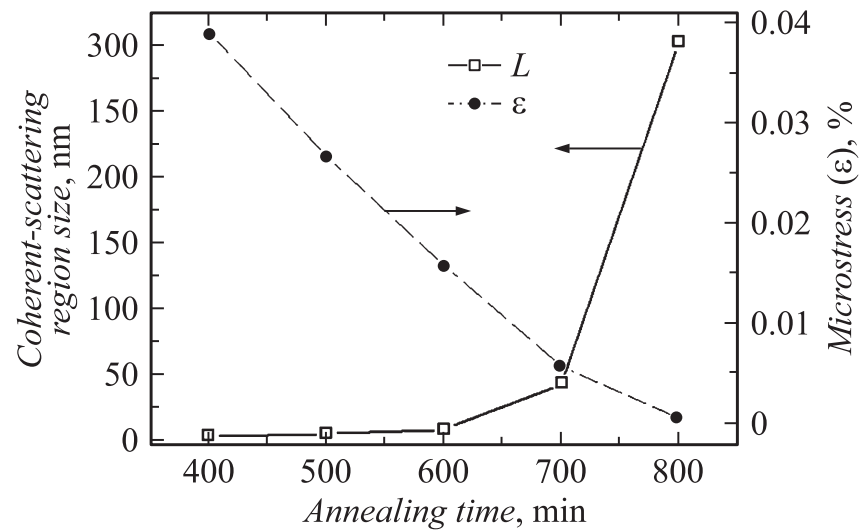

Рис. 5. Температурная зависимость размеров ОКР $(L)$ и микронапряжений $(\varepsilon)$.

полагался термически активируемым процессом:

$$
L=A \cdot \exp (-Q / R T)
$$

где $L$ - размер ОКР, $Q$ - энергия, характеризующая процесс роста нанокристаллов, $T$ - температура, $A-$ предэкспоненциальный множитель, $R$ - универсальная газовая постоянная.

Справедливость такой аппроксимации следует из графика, построенного в координатах $\log (L)$ от $1 / R T$ (рис. 6). За исключением данных для $T=400^{\circ} \mathrm{C}$ все точки хорошо ложатся на прямую. Рассчитанная величина $Q$ для температур от 500 до $800^{\circ} \mathrm{C}$, равная $67.3(10) \mathrm{kJ} / \mathrm{mol}$, незначительно больше энергии активации самодиффузии для нанокристаллических образцов никеля, равной $50.7 \mathrm{~kJ} / \mathrm{mol}$ [49]. Это свидетельствует о диффузионном механизме роста нанокристаллов.

Для определения влияния поверхности на метрику ячейки нанокристаллов Ni построена зависимость параметра элементарной ячейки от величины ОКР (рис. 7). Линия, проведенная на графике точками, соответствует параметру элементарной ячейки $\mathrm{Ni} a=0.352387 \mathrm{~nm}$ (COD ID 9008476). Из графика (рис. 7) следует, что с увеличением размера ОКР наблюдается рост параметра ячейки. Такая зависимость известна для благородных металлов и связана с положительной величиной энергии поверхностного напряжения [50]. На атомном уровне объяснение данного явления связано с уменьшением координационного числа для поверхностных атомов, что приводит к увеличению концентрации валентных электронов на оставшихся металлических связях, и тем самым к уменышению параметров ячеек поверхностного слоя. Поэтому чем больше доля поверхности (меньше размер ОКР), тем больше вклад в усредненный параметр элементарной ячейки величин, связанных с деформированными ячейками поверхности.

Интересно отметить, что изменение углового положения пиков 111 и 200 различно (рис. 8). Для более интенсивного пика $1112 \theta$ уменьшается с ростом температуры отжига, свидетельствуя об увеличении межплоскостного

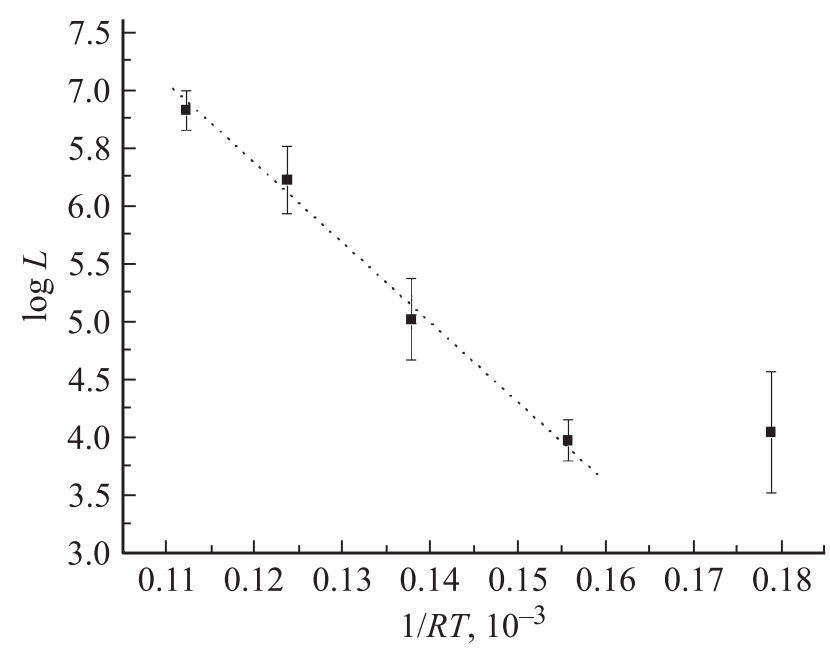

Рис. 6. Зависимость $\log (D)$ от $1 / R T$ для усредненных внутри серии размеров ОКР при различных температурах отжига.

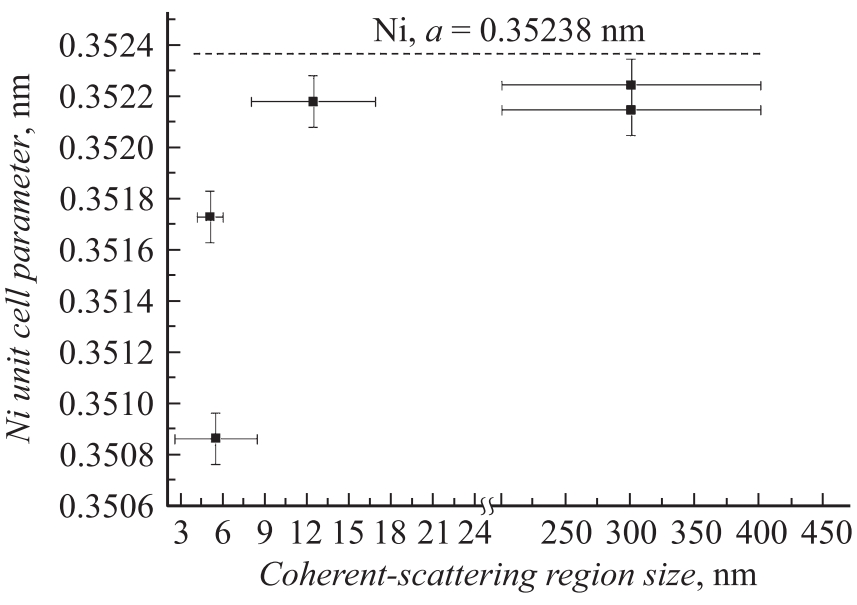

Рис. 7. Зависимость параметра элементарной ячейки Ni от размера ОКР после $5 \mathrm{~h}$ отжига при температурах $400-800^{\circ} \mathrm{C}$. 


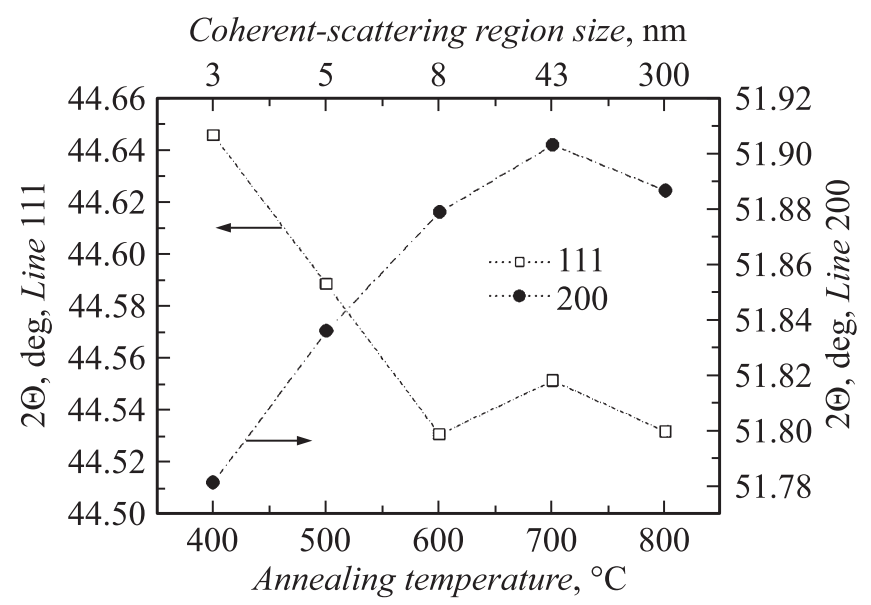

Рис. 8. Зависимость углового положения линий 111 и $200 \mathrm{Ni}$ от температуры отжига. Данные получены при комнатной температуре для образцов после 5 h отжига.

расстояния $d_{111}$. Учитывая, что увеличение температуры приводит к росту ОКР, зависимость положения пика 111 от температуры соответствует зависимости параметра элементарной ячейки от размера ОКР (рис. 7). Для пика $2002 \theta$, наоборот, увеличивается с ростом температуры отжига, т.е. с ростом ОКР межплоскостное расстояние $\mathrm{d}_{200}$ уменьшается. Такое поведение указывает на анизотропию, которая может проявляться в зависимости от огранки поверхности нанокристалла. При уточнении параметра ячейки по Ритвельду этот эффект был усреднен с большим весом для изменений в $2 \theta$ для линии 111 , как более интенсивной.

Расчеты показывают [51], что поверхностная энергия для плоской сетки 111 минимальна по сравнению с сеткой 100. Вероятно, при изменении огранки нанокристалла, когда доля плоскостей с индексами 100 на поверхности увеличится по сравнению плоскостями с индексами 111, соотношение может измениться, и эффект по влиянию размера ОКР на параметры ячейки будет противоположным. Вероятно, поэтому в работе [52], где наночастицы $\mathrm{Ni}$ синтезировались методом дугового разряда, получена зависимость, противоположная изображенной на рис. 7: параметр элементарной ячейки уменьшался с ростом размера ОКР. В нашем исследовании наночастицы кристаллизовались в аморфной матрице, что может оказывать значительное влияние на огранку поверхности.

\section{Заключение}

Методом высокотемпературной рентгенографии получены систематические данные о аморфно-кристаллическом переходе в $\mathrm{Ni}$. Установлено, что аморфная структура порошка $\mathrm{Ni}$ стабильна до температуры $200^{\circ} \mathrm{C}$. В температурном интервале $300-600^{\circ} \mathrm{C}$ происходит образование нанокристаллов $\mathrm{Ni}$, размер ОКР которых составляет 5-150 nm в зависимости от температуры изотермического отжига. При температурах $700-800^{\circ} \mathrm{C}$ образуются микрокристаллы размерами более $300 \mathrm{~nm}$. Предложено аррениусовское выражение для зависимости размера ОКР от температуры с характерной величиной энергии 67.3(10) kJ/mol, близкой к энергии активации самодиффузии для нанокристаллов. Установлено увеличение параметра элементарной ячейки нанокристаллов Ni с ростом размера ОКР.

\section{Финансирование работы}

Работа выполнена при поддержке Программы президиума РАН № 14.3 „Фундаментальные основы и новые эффективные методы химического анализа и исследования структуры веществ и материалов.

\section{Конфликт интересов}

Авторы заявляют, что у них нет конфликта интересов.

\section{Список литературы}

[1] Ковнеристый Ю.К. Физико-химические основы создания аморфных металлических сплавов. М.: Наука, 1983. 145 с.

[2] Попель С.И., Спиридонов М.А., Жукова Л.А. Атомное упорядочение в расплавленных и аморфных металлах. Екатеринбург: УГТУ-УПИ, 1997. 384 с.

[3] Greer A.L. // Science. 1995. Vol. 267. P. 1947-1953.

[4] Аморфные металлические сплавы. / Под ред. Ф.Е. Люборского. М.: Металлургия, 1987. 584 с.

[5] Herzer G. // Acta Mater. 2013. Vol. 61. P. 718-734.

[6] Mc Henry M.E., Willard M.A., Laughlin D.E. // Prog. Mater. Sci. 1999. Vol. 44. P. 291-433.

[7] Grinstaff M.W., Salamon M.B., Suslick K.S. // Phys. Rev. B: Condens. Matter Mater. Phys. 1993. Vol. 48. P. 269-273.

[8] Rojo J.M., Hernando A., ElGhannami M., GarcíaEscorial A., González M.A., García-Martínez R., Ricciarelli L. // Phys. Rev. Lett. 1996. Vol. 76. P. 4833-4836.

[9] Schuh C.A., Lund A.C. // Nat. Mater. 2003. Vol. 2. P. 449-452.

[10] Yao K.F., Ruan F., Yang Y.Q., Chen N. // Appl. Phys. Lett. 2006. Vol. 88. P. $86-89$.

[11] Schuh C.A., Hufnagel T.C., Ramamurty U. // Acta Mater. 2007. Vol. 55. P. 4067-4109.

[12] Guo H., Yan P.F., Wang Y.B., Tan J., Zhang Z.F., Sui M.L., Ma E. // Nat. Mater. 2007. Vol. 6. P. 735-739.

[13] Wuttig M., Yamada N. // Nat. Mater. 2007. Vol. 6. P. 824-832.

[14] Cao J.D., Kirkland N.T., Laws K.J., Birbilis N., Ferry M. // Acta Biomater. 2012. Vol. 8. P. 2375-2383.

[15] Zberg B., Uggowitzer P.J., Loöffler J.F. // Nat. Mater. 2009. Vol. 8. P. 887-891.

[16] Wang Y.B., Xie X.H., Li H.F., Wang X.L., Zhao M.Z., Zhang E.W., Bai Y.J., Zheng Y.F., Qin L. // Acta Biomater. 2011. Vol. 7. P. $3196-3208$.

[17] Kumar G., Tang H.X., Schroers J. // Nature. 2009. Vol. 457. P. $868-872$.

[18] Ingersoll J.C., Mani N., Thenmozhiyal J.C., Muthaiah A. // J. Power Sources. 2007. Vol. 173. P. 450-457.

[19] Dai H.B., Liang Y., Wang P., Cheng H.M. // J. Power Sources. 2008. Vol. 177. P. 17-23. 
[20] Fernandes R., Patel N., Miotell A. // Int. J. Hydrogen Energy. 2009. Vol. 34. P. 2893-2900.

[21] Fernandes R., Patel N., Miotell A., Filippi M. // J. Mol. Catal. A: Chem. 2009. Vol. 298. P. 1-6.

[22] Wen M., Wang Y.F., Zhang F., Wu Q.S. // J. Phys. Chem. C. 2009. Vol. 113. P. 5960-5966.

[23] Wang H.L., Yan J.M., Wang Z.L., Jiang Q. // Int. J. Hydrogen Energy. 2012. Vol. 37. P. 10229-10235.

[24] Maeland A.J. Rapidly Quenched Metals. Amsterdam. Elsevier. 1985. P. 1507.

[25] Liu B.X., Lai W.S., Zhang Q. // Mater. Sci. Eng. R. 2000. Vol. 29. P. 1-48.

[26] Liu B.X., Li Z.C., Gong H.R. // Surf. Coat. Technol. 2005. Vol. 196. P. 2-9.

[27] Schwarz R.B., Koch C.C. // Appl. Phys. Lett. 1986. Vol. 49. P. $146-148$.

[28] Schultz L. // Mater. Sci. Eng. 1988. Vol. 97. P. 15-23.

[29] Suslick K.S., Choe S.B., Cichowlas A.A., Grinstaff M.W. // Nature. 1991. Vol. 353. P. 414-416.

[30] Koltypin Y., Katabi G., Cao X., Prozorov R., Gedanken A. // J. Non-Cryst. Solid. 1996. Vol. 201. P.159-162.

[31] Salkar R.A., Jeevananda P., Aruna S.T., Koltypin Y., Gedanken A. // J. Mater. Chem. 1999. Vol. 9. P.1333-1335.

[32] Yan J.M., Zhang X.B., Han S., Shioyama H., Xu Q. // Angew. Chem. Int. Ed. 2008. Vol. 47. P. 2287-2289.

[33] Lu K. // Mater. Sci. Eng. R. 1996. Vol. 16. P. 161-221.

[34] Wang W.H., Dong C., Shek C.H. // Mater. Sci. Eng. R. 2004. Vol. 44. P. 45-89.

[35] Kim J.J., Choi Y., Suresh S., Argon A.S. // Science. 2002. Vol. 295. P.654-657.

[36] Jiang W.H., Atzmon M. // Scr. Mater. 2006. Vol. 54. P. 333-336. DOI: 10.1016/j.scriptamat.2005.09.052

[37] Abrosimova G.E. // Physics-Uspekhi. 2011. Vol. 54. N 12. P. 1227-1242. DOI: 10.3367/UFNe.0181.201112b.1265

[38] Zhang X., Wang T., Ma L., Zhang Q., Jiang T. // Bioresour. Technol. 2013. Vol. 127. P. 306-311.

[39] Haryanto A., Fernando S., Murali N., Adhikari S. // Energy Fuels. 2005. Vol. 19. P. 2098-2106. DOI: $10.1021 / \mathrm{ef0500538}$

[40] Kumar A., Mukasyan A.S., Wolf E.E. // Appl. Catal. A. 2011. Vol. 401. P. 20-28. DOI: 10.1016/j.apcata.2011.04.038

[41] Cross A., Kumar A., Wolf E.E., Mukasyan A.S. // Ind. Eng. Chem. Res. 2012. Vol. 51. P. 12004-12008. DOI: $10.1021 / \mathrm{ie} 301478 \mathrm{n}$

[42] Jiang Z., Yang H., Wei Z., Xie Z., Zhong W., Wei S. // Appl. Catal. A. 2005. Vol. 279. P. 165-171. DOI: 10.1016/j.apcata.2004.10.027

[43] Wei Z., Li Z., Jiang Z., Ye J., Zhong W., Song J., Wei S. // J. Alloys Compd. 2008. Vol. 460. P. 553-558. DOI: $10.1016 /$ j.jallcom.2007.06.017

[44] Rodriguez-Carvajal. // J. Recent Developments of the Program FULLPROF, in Commission on Powder Diffraction (IUCr). IUCr Newsletter (2001). Vol. 26. P. 12-19.

[45] Wyckoff R.W.G. Cubic closest packed, ccp, structure. Second edition. Interscience Publishers, New York. Crystal Structures, 1963. Vol. 1. P. 7-83.

[46] Crystallography Open Database. http://www.crystallography.net/cod/

[47] Thompson P., Cox D.E., Hastings J.B. // J. Appl. Cryst. 1987. Vol. 20. P. 79-83.
[48] Martínez-Blanco D., Gorria P., Blanco J.A., Perez M.J., Campo J. // J. Phys.: Condens. Matter. 2008. Vol. 20. P. 335213. http://dx.doi.org/10.1088/0953-8984/20/33/335213

[49] Батаев В.А., Буров В.Г., Батаев И.А., Дробяз Е.А., Веселов C.B. Процессы и технологии получения наноразмерных порошков и наноструктурированных материалов. Новосибирск: Из-во НГТУ, 2017. 283 с.

[50] Manuel Diehm P., Agoston P., Albe K. // Chem. Phys. Chem. 2012. Vol. 13. P. $2443-2454$. DOI: $10.1002 /$ cphc.2012200257

[51] Wei Z., Xia T., Ma J., Feng W., Dai J., Wang Q., Yan P. // Mater. Charact. 2007. Vol. 58. P. 1019-1024. DOI: $10.1016 /$ j.matchar.2006.08.004

[52] Cammarata R.C. // Annu. Rev. Mater. Sci. 1994. Vol. 24. P. 215-234. DOI: 10.1146/annurev.ms.24.080194.001243 